\title{
Optimization of Process Parameters in Plasma ARC CUTTING USING TOPSIS MeTHOD
}

\author{
Kenan Muhamedagic, Derzija Begic-Hajdarevic, Mugdim Pasic \& Ahmet Cekic
}
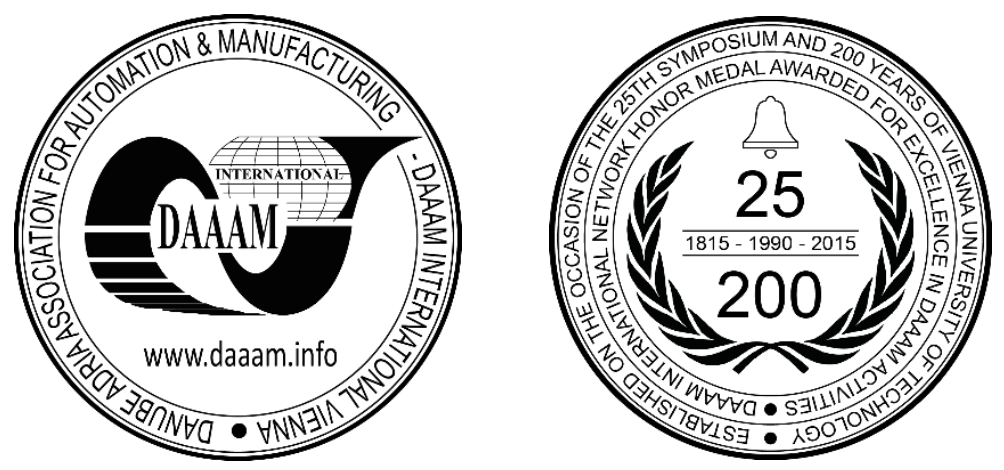

This Publication has to be referred as: Muhamedagic, K[enan]; Begic-Hajdarevic, D[erzija]; Pasic, M[ugdim] \& Cekic, A[hmet] (2018). Optimization of Process Parameters in Plasma Arc Cutting using TOPSIS Method, Proceedings of the 29th DAAAM International Symposium, pp.0202-0209, B. Katalinic (Ed.), Published by DAAAM International, ISBN 978-3-902734-20-4, ISSN 1726-9679, Vienna, Austria

DOI: $10.2507 / 29$ th.daaam.proceedings.029

\begin{abstract}
This paper presents the use of Technique for Order Preference by Similarity to Ideal Solution (TOPSIS) method to determine the optimum process parameters in plasma arc cutting of stainless steel. Two input process parameters, cutting speed and plasma gas pressure are considered and experiments are conducted based on Taguchi L9 orthogonal array. After performing the experiments, the surface roughness, cut perpendicularity and kerf width are measured. The analysis of variance (ANOVA) are performed in order to identify the effect of each input process parameters on the output responses. The results indicate that TOPSIS method is appropriate for solving multi-criteria optimization of process parameters. Results also showed that cutting speed of $2500 \mathrm{~mm} / \mathrm{min}$ and plasma gas pressure of 6 bar are the optimum combination of process parameters.
\end{abstract}

Keywords: plasma arc cutting; stainless steel; TOPSIS method; ANOVA

\section{Introduction}

The cutting process is one of the fundamental machining operations so that optimization of parameters leads to better machining performance. Plasma arc cutting is a very important thermal cutting process and it can be used successfully in the cutting of different materials. The achievement of high machining performance and selection of appropriate process parameters is a very challenging task for researchers. The economic benefit of using plasma arc cutting is providing components with appropriate cut quality. There are various parameters (characteristics) involved in the estimation of the cut quality. Some of the cut quality characteristics are surface roughness, kerf width, heat affected zone, cut perpendicularity and etc. To reduce the kerf width and to improve the kerf quality, the hydro-magnetically confined plasma arc was used to cut engineering ceramic plate [1]. Statistical control charts are used to find combination of the cutting speed and laser power to obtain stable cutting process and best quality of the cut [2]. Laser cut perpendicularity depending on the cutting speed, laser power and assist gas pressure is investigated by developing mathematical model using linear regression analysis [3]. It is shown that regression analysis is suitable for analysis of cut perpendicularity. The high tolerance plasma arc cutting system is used to cut the mild steel sheets with thickness of $15 \mathrm{~mm}$ [4], the effect of the arc voltage, cutting speed, plasma gas flow rate, shield gas flow rate and shield gas mixture on kerf position and shape is analysed. 
Analysis of variance was used to identify the effect of input process parameters such as gas pressure, traverse speed and thickness of material on the material removal rate and surface roughness during plasma arc cutting of AISI 304 stainless steel [5]. The effect of cutting speed and gas pressure on surface roughness and material removal rate in plasma arc cutting of Quard - 400 material using analysis of variance was investigated in [6]. It was found that cutting speed has most significance. For modelling and optimizing of machining processes, Taguchi method [7], genetic algorithm [8], particle swarm optimization [9] are commonly used. The TOPSIS method is a multi-objective optimization method. It is simple for use and an appropriate method to solve multi-response problems efficiency. Milling, drilling, turning, electric discharge machining, abrasive jet machining, micro machining, and other advanced types of machining process are optimized by TOPSIS method [10]. The application of a multi-criteria decision making based TOPSIS method for the optimization of some non-conventional machining processes was proposed by [11]. It was observed that the optimal combination of machining variables was almost similar to those derived by former investigators. An integrated Taguchi and TOPSIS method was used for optimization of process parameters like cutting speed, feed rate and depth of cut in turning of EN25 steel using coated carbide tools [12]. It was observed that the proposed experimental and statistical approach is simple, useful, and reliable methodology to optimized turning process parameters efficiency.

Based on literature review, it was found that very few research studies are reported for the application of TOPSIS method in plasma arc cutting process parameters optimization. The purpose of this study is to optimize cutting parameters in plasma arc cutting of stainless steel using TOPSIS method as well as to analyse significance and interaction of the cutting parameters using ANOVA.

\section{Experimental procedure}

Experiments were conducted on HiFocus 280 i neo plasma device. The material used for the experiments was X5CrNi18-10 stainless steel plates with thickness of $5 \mathrm{~mm}$. For this experiment selected two variable process parameters, cutting speed and plasma gas pressure. Process parameters with their units and values at different levels are listed in table 1. Properties of the workpiece material and others constant process parameters are detailed in [13].

\begin{tabular}{|c|c|c|c|c|}
\hline \multirow{2}{*}{ Symbol } & \multirow{2}{*}{ Process parameter } & \multicolumn{3}{|c|}{ Level } \\
\hline & & 1 & 2 & 3 \\
\hline A & $\begin{array}{c}\text { Cutting speed } \\
V, \mathrm{~mm} / \mathrm{min}\end{array}$ & 2000 & 2500 & 3000 \\
\hline B & $\begin{array}{c}\text { Plasma gas pressure } \\
p, \text { bar }\end{array}$ & 6 & 8 & 10 \\
\hline
\end{tabular}

Table 1. Cutting parameters and their levels

In this experiment, three cut quality characteristics were analysed. That are the surface roughness parameter $R_{Z}$, cut perpendicularity and kerf width. Average surface roughness $\left(R_{Z}\right)$ values were measured using Mitutoyo SJ-210 measuring device. Roughness is measured along the length of a cut at five different places, approximately on the $1 / 3$ of thickness from bottom side of cut. The Mitutoyo TM-505 microscope was used to measure the cut perpendicularity $(u)$ and kerf width $(a)$, which were measured at 9 different places along the length of the cut.

\section{Results and discussions}

The mean values of the surface roughness parameter $R z$, kerf width and cut perpendicularity are given in table 2 .

\begin{tabular}{|c|c|c|c|c|c|}
\hline $\begin{array}{c}\text { Exp. } \\
\text { No. }\end{array}$ & $\begin{array}{c}\text { Cutting speed } \\
\boldsymbol{V}, \mathbf{m m} / \mathbf{m i n}\end{array}$ & $\begin{array}{c}\text { Plasma gas } \\
\text { pressure } \\
\boldsymbol{p}, \mathbf{b a r}\end{array}$ & $\begin{array}{c}\text { Surface roughness } \\
\boldsymbol{R}_{\boldsymbol{Z}}, \boldsymbol{\mu m}\end{array}$ & $\begin{array}{c}\text { Cut } \\
\text { perpendicularity } \\
\boldsymbol{u}, \boldsymbol{\mu m}\end{array}$ & $\begin{array}{c}\text { Kerf width } \\
\boldsymbol{a}, \boldsymbol{\mu m}\end{array}$ \\
\hline 1. & 2000 & 6 & 15,996 & 615,11 & 1991,1 \\
2. & 2000 & 8 & 13,756 & 514,05 & 2055,5 \\
3. & 2000 & 10 & 9,861 & 527,81 & 1971,4 \\
\hline 4. & 2500 & 6 & 8,192 & 424,82 & 1934,2 \\
5. & 2500 & 8 & 10,572 & 411,00 & 1990,7 \\
6. & 2500 & 10 & 11,851 & 421,59 & 1954,4 \\
\hline 7. & 3000 & 6 & 9,365 & 812,74 & 1871,4 \\
8. & 3000 & 8 & 10,272 & 426,77 & 1834,1 \\
9. & 3000 & 10 & 11,022 & 503,23 & 1962,8 \\
\hline
\end{tabular}

Table 2. Experimental results 


\subsection{Techniques for Order Preference by Similarity to Ideal Solution (TOPSIS) method}

Technique for Order Preference by Similarity to an Ideal Solution (TOPSIS) method was based on the principal of positive ideal solution and negative ideal solution. The positive ideal solution and negative ideal solution is a hypothetical solution for which all the experiments results are within limit in between maximum and minimum. It gives a solution that is not only closest to the hypothetically maximum (best) result but also farthest from the hypothetically minimum (worst) result. The basic thought is to find a solution according to the closeness-coefficient between the feasible solution and the ideal solution.

In this paper TOPSIS method is used to optimize the multi machining characteristics. There are three response characteristics that should be minimized, the surface roughness parameter $R z$, cut perpendicularity and kerf width. The steps followed for the TOPSIS in this paper are given below.

Step 1: The first step in the TOPSIS method is to determine a normalized matrix. Equation (1) is used to normalize the output values.

$$
r_{i j}=\frac{x_{i j}}{\sqrt{\sum_{i=1}^{m} x_{i j}^{2}}}
$$

where $i=1 \ldots m$ and $j=1 \ldots n . x_{i j}$ represents the acual value of the $i$-th experimental result for $j$-th process response and $r_{i j}$ represents the corresponding normalized value. The normalized matrix is given in table 3 .

Step 2: In this step it is determined the weighted normalized decision matrix. The weighted normalized decision matrix is calculated by multiplying the normalized decision matrix by its associated weights. This factor should be determined so that the sum of all weight factors is equal to 1 . All output responses are considered as equal, the associated weights are $R_{Z}=0.33, u=0.33, a=0.33$ and the sum of weight is 1 . The weighted normalized matrix is determined by (2) and shown in table 3 .

$$
a_{i j}=w_{j} \cdot r_{i j}=w_{j} \cdot \frac{x_{i j}}{\sqrt{\sum_{i=1}^{m} x_{i j}^{2}}}
$$

\begin{tabular}{|c|c|c|c|c|c|c|}
\hline \multirow{2}{*}{$\begin{array}{c}\text { Exp. } \\
\text { No. }\end{array}$} & \multicolumn{3}{|c|}{ Normalized matrix } & \multicolumn{2}{c|}{ Weighted normalized matrix } \\
\cline { 2 - 7 } & $\boldsymbol{R}_{\boldsymbol{Z}}$ & $\boldsymbol{u}$ & $\boldsymbol{a}$ & $\boldsymbol{R}_{\boldsymbol{Z}}$ & $\boldsymbol{u}$ & $\boldsymbol{a}$ \\
\hline 1. & 0,4664 & 0,3856 & 0,3399 & 0,1554 & 0,1285 & 0,1133 \\
2. & 0,4011 & 0,3223 & 0,3509 & 0,1337 & 0,1074 & 0,1169 \\
3. & 0,2875 & 0,3309 & 0,3365 & 0,0958 & 0,1103 & 0,1122 \\
\hline 4. & 0,2388 & 0,2663 & 0,3302 & 0,0796 & 0,0888 & 0,11 \\
5. & 0,3082 & 0,2577 & 0,3398 & 0,1027 & 0,0859 & 0,1133 \\
6. & 0,3455 & 0,2643 & 0,3336 & 0,1152 & 0,0881 & 0,1112 \\
\hline 7. & 0,273 & 0,5096 & 0,3194 & 0,091 & 0,1698 & 0,1065 \\
8. & 0,2995 & 0,2676 & 0,3131 & 0,0998 & 0,0892 & 0,1044 \\
9. & 0,3214 & 0,3155 & 0,3351 & 0,1071 & 0,1052 & 0,1117 \\
\hline
\end{tabular}

Table 3. Normalized matrix and weighted normalized matrix

Step 3: Determine the positive ideal solution $\left(A_{j}^{+}\right)$and the negative ideal solution $\left(A_{j}^{-}\right)$. Positive ideal solution is for the best possible value and the negative ideal solution worst value of every process response from the weighted decision matrix. $A_{j}^{+}$and $A_{j}^{-}$are determined using (3) and (4):

$$
\begin{aligned}
& A^{+}=\left\{A_{1}^{+}, \ldots, A_{n}^{+}\right\} \\
& \text {where } A_{i}^{+}=\left\{\max \left(A_{i j}\right) \text { if } j \in J ; \min \left(A_{i j}\right) \text { if } j \in J^{*}\right\}
\end{aligned}
$$


$A^{-}=\left\{A_{1}^{-}, \ldots, A_{n}^{-}\right\}$,

where $A_{i}^{-}=\left\{\min \left(A_{i j}\right)\right.$ if $j \in J$; $\max \left(A_{i j}\right)$ if $\left.j \in J^{*}\right\}$

In (3) and (4), $J^{*}$ is a set of cost attributes and $J$ is a set of beneficital attributes. In this case, the positive ideal solution $\left(A_{j}^{+}\right)$for each output parameter is the minimum value for each experimental result. The negative ideal solution $\left(A_{j}^{-}\right)$is the maximum value for each experimental result. Positive and negative ideal solution are shown in table 4.

\begin{tabular}{|c|c|c|}
\hline Process responses & Positive ideal solution $\left(\boldsymbol{A}^{+}\right)$ & Negative ideal solution $\left(\boldsymbol{A}^{-}\right)$ \\
\hline$R_{Z}$ & 0,0796 & 0,1554 \\
$u$ & 0,0859 & 0,1698 \\
$a$ & 0,1044 & 0,1169 \\
\hline
\end{tabular}

Table 4. Positive and negative ideal solution

Step 4: Calculate the separation of positive ideal solution $\left(S^{+}\right)$and negative ideal solution $\left(S^{-}\right)$is given by (5) and (6).

$$
\begin{gathered}
S^{+}=\sqrt{\sum_{j=1}^{n}\left(a_{i j}-A_{j}^{+}\right)^{2}} \\
S^{-}=\sqrt{\sum_{j=1}^{n}\left(a_{i j}-A_{j}^{-}\right)^{2}}
\end{gathered}
$$

Separation of positive ideal solution $\left(S^{+}\right)$and negative ideal solution $\left(S^{-}\right)$are shown in table 5.

\begin{tabular}{|c|c|c|}
\hline Exp. No. & $\begin{array}{c}\text { Separation of positive ideal } \\
\text { solution }\left(\boldsymbol{S}^{+}\right)\end{array}$ & $\begin{array}{c}\text { Separation of negative ideal } \\
\text { solution }\left(\boldsymbol{S}^{-}\right)\end{array}$ \\
\hline 1. & 0,0875 & 0,0414 \\
2. & 0,0595 & 0,0661 \\
3. & 0,0303 & 0,0843 \\
\hline 4. & 0,0063 & 0,1112 \\
5. & 0,0248 & 0,0991 \\
6. & 0,0363 & 0,0913 \\
\hline 7. & 0,0847 & 0,0652 \\
8. & 0,0205 & 0,0987 \\
9. & 0,0344 & 0,0809 \\
\hline
\end{tabular}

Table 5. Separation matrix

Step 5: Determination of relative closeness coefficient $\left(C_{i}\right)$ is get by (7).

$$
C_{i}=\frac{S_{i}^{-}}{S_{i}^{+}+S_{i}^{-}}
$$

Relative closeness coefficient values are given in table 6. Optimum process parameter levels are determined using higher level of relative closeness coefficient and the values are $V=2500 \mathrm{~mm} / \mathrm{min}$ and $p=6$ bar. 


\begin{tabular}{|c|c|c|c|c|}
\hline Exp. No. & $\begin{array}{c}\text { Cutting } \\
\text { speed } \\
\boldsymbol{V}, \mathbf{m m} / \mathbf{m i n}\end{array}$ & $\begin{array}{c}\text { Plasma gas } \\
\text { pressure } \\
\boldsymbol{p}, \text { bar }\end{array}$ & $\begin{array}{c}\text { Closeness } \\
\text { coefficient } \\
\boldsymbol{C}_{\boldsymbol{i}}\end{array}$ & Rank \\
\hline 1. & 2000 & 6 & 0,3214 & 9 \\
2. & 2000 & 8 & 0,5259 & 7 \\
3. & 2000 & 10 & 0,7356 & 4 \\
\hline 4. & 2500 & 6 & 0,9461 & 1 \\
5. & 2500 & 8 & 0,8001 & 3 \\
6. & 2500 & 10 & 0,7155 & 5 \\
\hline 7. & 3000 & 6 & 0,4350 & 8 \\
8. & 3000 & 8 & 0,8282 & 2 \\
9. & 3000 & 10 & 0,7018 & 6 \\
\hline
\end{tabular}

Table 6. Relative closeness coefficient and rank of TOPSIS

\section{Analysis of Variance (ANOVA)}

The ANOVA for surface roughness is presented in table 7. Comparing values of calculated $F_{\text {stat }}$ with $F_{0,05 ; 2 ; 36}=$ 3,25945 it can be concluded that the main effect of cutting speed is significant, while the main effect of the plasma gas pressure is not significant. Same conclusion can be obtained comparing calculated $p$ value with level of significance $\alpha=$ 0,05 . Since $p$ value for cutting speed is less than $\alpha=0,05$ it can be concluded that the main effect of cutting speed is significant.

However, $p$ value for plasma gas pressure is greater than $\alpha=0,05$ and it can be concluded that the main effect of plasma gas pressure is not significant. Since critical value $F_{0,05 ; 4 ; 36}=2,63353$ is less than $F_{\text {stat }}=7,26559$ it can be concluded that there is a significant interaction between cutting speed and plasma gas pressure. Same conclusion can be obtained by comparing $p$ value $=0,00021$ with level of significance $\alpha=0,05$.

\begin{tabular}{|l|c|r|r|r|r|}
\hline Source of Variation & $\begin{array}{c}\text { Degrees of } \\
\text { freedom }\end{array}$ & \multicolumn{1}{c|}{$\begin{array}{c}\text { Sum of } \\
\text { Squares }\end{array}$} & \multicolumn{1}{c|}{$\begin{array}{c}\text { Mean } \\
\text { Square }\end{array}$} & \multicolumn{1}{c|}{$\boldsymbol{F}_{\text {stat }}$} & $\boldsymbol{p}$ value \\
\hline Cutting Speed & 2 & 89,51425 & 44,75712 & 9,64759 & 0,00044 \\
\hline Plasma gas pressure & 2 & 2,91423 & 1,45711 & 0,31409 & 0,73244 \\
\hline Interaction & 4 & 134,82620 & 33,70655 & 7,26559 & 0,00021 \\
\hline Error & 36 & 167,01137 & 4,63920 & & \\
\hline Total & 44 & 394,26604 & & & \\
\hline
\end{tabular}

Table 7. Analysis of variance for surface roughness

At figure 1 a graph of average responses of each treatment combination is presented. For the cutting speeds $v=$ $3000 \mathrm{~mm} / \mathrm{min}$ and $v=2500 \mathrm{~mm} / \mathrm{min}$ surface roughness increases with the increase of the plasma gas pressure, while for the cutting speed $v=2000 \mathrm{~mm} / \mathrm{min}$ surface roughness decreases with the increase of the plasma gas pressure. From the graph it can be observed existence of significant interaction effect since there is no parallelism of the lines.

Table 8 depicts ANOVA for the cut perpendicularity. Since calculated $F_{\text {stat }}$ values for both cutting speed and plasma gas pressure are greater than critical value of $F_{0,05 ; 2 ; 72}=3,12391$, it can be concluded that the main effects of cutting speed and plasma gas pressure are significant. Since for the interaction term critical value of $F_{0,05 ; 4 ; 72}=2,49892$ is less than $F_{\text {stat }}=34,24679$, it can be concluded that there is significant interaction between cutting speed and plasma gas pressure. Based on $p$ values presented in table 8 same conclusion can be obtained by comparing calculated $p$ values with $\alpha=0,05$ level of significance about significance of the main effects of cutting speed and plasma gas pressure as well as about interaction effect. 


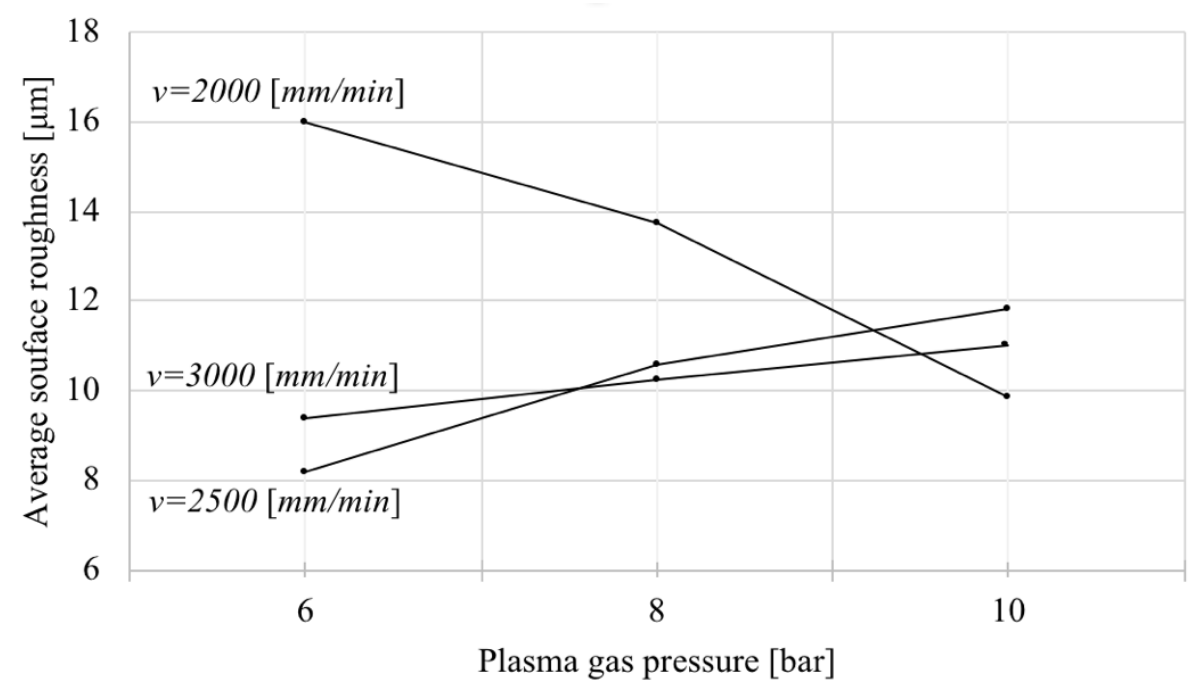

Fig. 1. Average surface roughness plot

\begin{tabular}{|l|c|c|c|c|c|}
\hline Source of Variation & $\begin{array}{c}\text { Degrees of } \\
\text { freedom }\end{array}$ & $\begin{array}{c}\text { Sum of } \\
\text { Squares }\end{array}$ & Mean Square & $\boldsymbol{F}_{\text {stat }}$ & $\boldsymbol{p}$ value \\
\hline Cutting speed & 2 & 402285,78074 & 201142,89037 & 71,39580 & 0,00000 \\
\hline Plasma gas pressure & 2 & 421161,08667 & 210580,54333 & 74,74570 & 0,00000 \\
\hline Interaction & 4 & 385932,95037 & 96483,23759 & 34,24679 & 0,00000 \\
\hline Error & 72 & 202845,10222 & 2817,29309 & & \\
\hline Total & 80 & 1412224,92000 & 201142,89037 & & \\
\hline
\end{tabular}

Table 8 . Analysis of variance for cut perpendicularity

Cut perpendicularity graph of average responses of each treatment combination is presented at figure 2. It can be seen that for the cutting speeds $v=2000 \mathrm{~mm} / \mathrm{min}$ and $v=2500 \mathrm{~mm} / \mathrm{min}$ cut perpendicularity decreases with the increase of the plasma gas pressure. For the cutting speed $v=3000 \mathrm{~mm} / \mathrm{min}$ surface roughness decreases with the increase of the plasma gas pressure from 6 [bar] to 8 [bar] and then increases with the increase of the plasma gas pressure from 8 bar to 10 bar. Non-parallel lines shown on the graph indicate a significant interaction effect.

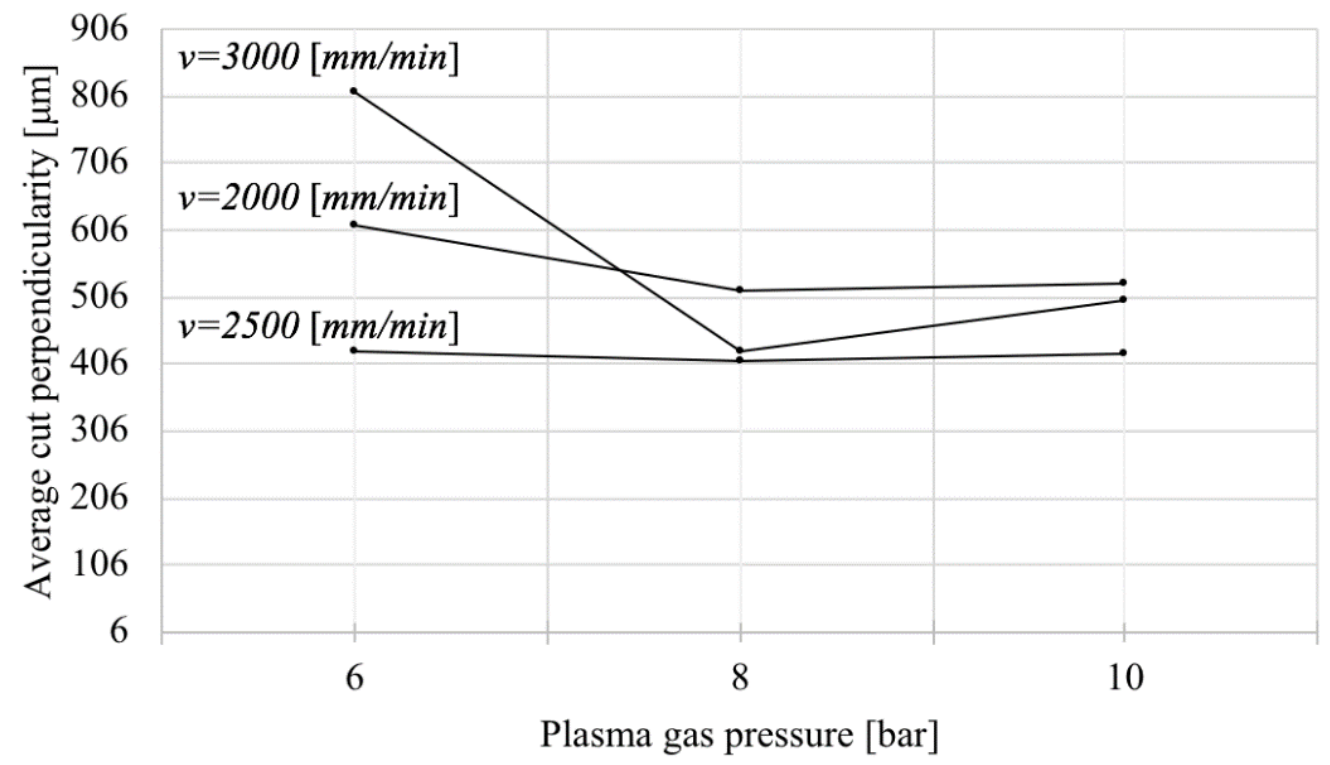

Fig. 2. Average cut perpendicularity plot 
ANOVA for the kerf width is depicted in table 9. Comparing calculated $F_{\text {stat }}$ values for cutting speed $\left(F_{\text {stat }}=\right.$ $108,62147)$ and plasma gas pressure $\left(F_{\text {stat }}=9,06117\right)$ with the critical value of $F_{0,05 ; 2 ; 72}=3$,12391, it can be concluded that the main effects of cutting speed and plasma gas pressure on the kerf width are significant since $F_{\text {stat }}$ for both cutting speed and plasma gas pressure are greater than critical value of $F$. There is significant interaction between cutting speed and plasma gas pressure, since interaction term critical value of $F_{0,05 ; 4 ; 72}=2,49892$ is less than calculated $F_{\text {stat }}=32,98752$. Calculated $p$ values presented in table 9 indicate that the main effects of cutting speed and plasma gas pressure as well as interaction between these two variables are all significant since these values are less than $\alpha=0,05$ level of significance.

\begin{tabular}{|l|c|r|r|r|r|}
\hline Source of Variation & $\begin{array}{c}\text { Degrees of } \\
\text { freedom }\end{array}$ & $\begin{array}{c}\text { Sum of } \\
\text { Squares }\end{array}$ & $\begin{array}{c}\text { Mean } \\
\text { Square }\end{array}$ & $\boldsymbol{F}_{\text {stat }}$ & $\boldsymbol{p}$ value \\
\hline Cutting speed & 2 & 186015,83630 & 93007,91815 & 108,62147 & 0,00000 \\
\hline Plasma gas pressure & 2 & 15517,38741 & 7758,69370 & 9,06117 & 0,00031 \\
\hline Interaction & 4 & 112983,20296 & 28245,80074 & 32,98752 & 0,00000 \\
\hline Error & 72 & 61650,52222 & 856,25725 & & \\
\hline Total & 80 & 376166,94889 & & & \\
\hline
\end{tabular}

Table 9. Analysis of variance for kerf width

A graph of average responses of kerf width of each treatment combination is presented at figure 3 . It can be seen that for the cutting speeds $v=2000 \mathrm{~mm} / \mathrm{min}$ and $v=2500 \mathrm{~mm} / \mathrm{min}$ kerf width increases with the increase of the plasma gas pressure from 6 bar to 8 bar, and then decreases with the increase of the plasma gas pressure from 8 bar to 10 bar. For the cutting speed $v=3000 \mathrm{~mm} / \mathrm{min}$ kerf width decreases with the increase of the plasma gas pressure from 6 bar to 8 bar and then increases with the increase of the plasma gas pressure from 8 bar to 10 bar. No parallelism of the lines shown at the graph indicates existence of significant interaction effect.

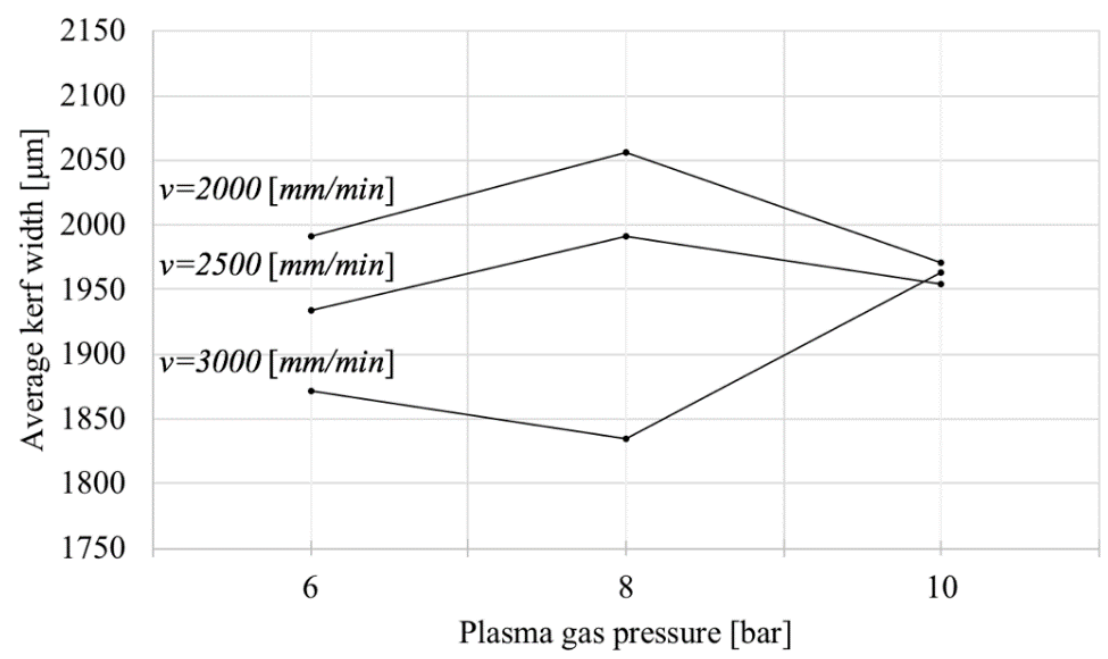

Fig. 3. Average kerf width plot

\section{Conclusion}

In this paper TOPSIS analysis was performed for multicriteria optimization of process parameters of plasma cutting stainless steel X5CrNi18-10. Relative closeness coefficient and rank of TOPSIS method showed that optimal parameters combination is achieved having plasma gas pressure of 6 bar and cutting speed of $2500 \mathrm{~mm} / \mathrm{min}$.

Analysis of variance (ANOVA) was done for all three cut quality characteristics: surface roughness, cut perpendicularity and kerf width in relations to two factors: cutting speed and plasma gas pressure. Based on ANOVA results significant factors were determined as well as the existence of significant interaction between factors. Cutting speed and plasma gas pressure showed to have significant main effect in the case of both cut perpendicularity and kerf width as well as significant interaction. In the case of the surface roughness main effect of the cutting speed was significant, while main effect of the plasma gas pressure was insignificant. Interaction between cutting speed and plasma gas pressure showed to be significant in the case of surface roughness. Future research would include analysis of additional factors that would influence cut quality characteristics as well as other types of material of different thickness. 


\section{References}

[1] Xu, W.J.; Fang, J.C. \& Lu, Y.S. (2002). Study on ceramic cutting by plasma arc. Journal of Materials Processing Technology, 129, 1-3, (October 2002) 152-156, ISSN: 0924-0136

[2] Begic-Hajdarevic, D.; Vucijak, B.; Pasic, M.; Bijelonja, I. (2017). Analysis of the influence of cutting parameters on surface roughness in laser cutting process of tungsten alloy using control charts. Technical Gazzete, 24, 2, (september 2017) 339-344, ISSN 1330-3651

[3] Pasic, M.; Begic-Hajdarevic, D.; Bijelonja, I. (2017). Estimation of the laser cut perpendicularity using linear regression analysis, Proceedings of the 28th DAAAM International Symposium, ISBN 978-3-902734-11-2, ISSN 1726-9679, Katalinic, B. (Ed.), pp. 1083-1089, DAAAM International, Vienna, DOI: $10.2507 / 28$ th.daaam.proceedings. 150

[4] Bini, R.; Colosimo, B.M.; Kutlu, A.E. \& Monno, M. (2008). Experimental study of the features of the kerf generated by a 200A high tolerance plasma arc cutting system. Journal of Materials Processing Technology, 196, (2008) 345 355, ISSN 0924-0136

[5] Bhowmick, S.; Basu, J.; Majumdar, G. \& Banyopadhyay, A. (2018). Experimental study of plasma arc cutting of AISI 304 stainless steel. Materials Today: Proceedings, 5, 2, (2018) 4541-4550, ISSN: 2214-7853

[6] Patel, P.; Soni, S.; Kotkunde, N. \& Khanna, N. (2018). Study the effect of process parameters in plasma arc cutting on Quard-400 material using analysis of variance. Materials Today: Proceedings, 5, 2, (2018) 6023-6029, ISSN: 2214-7853

[7] Begic-Hajdarevic, D.; Pasic, M.; Cekic, A.; Mehmedovic, M. (2016). Optimization of process parameters for cut quality in $\mathrm{CO}_{2}$ laser cutting using Taguchi method, Proceedings of the 27th DAAAM International Symposium, ISBN 978-3-902734-08-2, ISSN 1726-9679, Katalinic, B. (Ed.), pp. 0157-0164, DAAAM International, Vienna, DOI: $10.2507 / 27$ th.daaam.proceedings.024

[8] Ficko, M. \& Palcic, I. (2013). Designing a layout using the modified triangle method, and genetic algorithms. International Journal of Simulation Modelling, 12, 4 (2014), 237-251, ISSN 1726-4529

[9] Hrelja, M.; Klancnik, S.; Irgolic, T.; Paulic, M.; Balic, J. \& Brezocnik, M. (2014). Turning Parameters Optimization using Particle Swarm Optimization, Procedia Engineering 69 (2014) 670 - 677, ISSN: 1877-7058, doi: 10.1016/j.proeng.2014.03.041

[10] Atul, S.; Pankaj, A.; Rana, R.S. \& Rajesh, P. (2017). Applications of TOPSIS Algorithm on various Manufacturing Processes: A Review. Materials Today: Proceedings, 4, (2017) 5320-5329, ISSN: 2214-7853

[11] Akhtar, K. \& Kalipada M. (2016). Application of MCDM-based TOPSIS Method for the Optimization of Multi Quality Characteristics of Modern Manufacturing Processes. International Journal of Engineering Research in Africa Submitted, 23, (2016) 33-51, ISSN: 1663-4144, doi:10.4028/www.scientific.net/JERA.23.33

[12] Singaravel, B. \& Thangiah, S. (2017). Application of integrated Taguchi and TOPSIS method for optimization of process parameters for dimensional accuracy in turning of EN25 steel. Journal of the Chinese Institute of Engineers, 40, 4, (2017) 267-274, ISSN: 0253-3839, doi.org/10.1080/02533839.2017.1308233

[13] Muhamedagic, K.; Begic-Hajdarevic, D.; Cekic, A. \& Mehmedovic, M. (2017). Multi-response optimization of plasma cutting parameters using Grey relational analysis, Proceedings of the 28th DAAAM International Symposium, ISBN 978-3-902734-11-2, ISSN 1726-9679, Katalinic, B. (Ed.), pp. 1074-1082, DAAAM International, Vienna, DOI: 10.2507/28th.daaam.proceedings.149 